\title{
Update on Autoimmune Hepatitis
}

\author{
Rodrigo Liberal, Diego Vergani and Giorgina Mieli-Vergani*
}

\begin{abstract}
Paediatric Liver, GI \& Nutrition Centre and Institute of Liver Studies, King's College London School of Medicine at King's College
\end{abstract} Hospital, London, UK

\begin{abstract}
Autoimmune hepatitis (AIH), a liver disorder affecting both children and adults, is characterized by inflammatory liver histology, elevated transaminase levels, circulating nonorgan-specific autoantibodies, and increased levels of immunoglobulin G, in the absence of a known etiology. Two types of $\mathrm{AIH}$ are recognized according to seropositivity: smooth muscle antibody and/or antinuclear antibody define AIH type 1 and antibodies to liver-kidney microsome type 1 and/or liver cytosol type 1 define AIH type 2. AIH type 1 affects both adults and children, while AIH type 2 is mainly a paediatric disease, though it does occasionally affects young adults. AIH should be considered during the diagnostic workup of any patient with increased liver enzyme levels. AIH is exquisitely responsive to immunosuppressive treatment with prednisolone with or without azathioprine, with symptom free longterm survival for the majority of patients. For those who do not respond to standard treatment, or who are difficult-totreat, mycophenolate mofetil and, in the absence of a response, calcineurin inhibitors should be tried in addition to steroids. The pathogenesis of AIH is not fully understood, although there is mounting evidence that genetic susceptibility, molecular mimicry and impaired immunoregulatory networks contribute to the initiation and perpetuation of the autoimmune attack. Liver damage is thought to be mediated primarily by CD4 T-cells, although recent studies support the
\end{abstract}

Keywords: Autoimmune hepatitis; Autoantibodies; Immunogenetics; Regulatory T cells; Immunosuppresion.

Abbreviations: AIH, autoimmune hepatitis; ALT, alanine aminotransferase; AMA, anti-mitochondrial antibodies; ANA, antinuclear antibody; ANCA, anti-neutrophil cytoplasmic antibodies; anti-ASGPR, autoantibodies to asialoglycoprotein receptor; anti-LC-1, anti-liver cytosol type 1 antibody; anti-LKM-1, anti-liver kidney microsomal type 1 antibody; AP, alkaline phosphatase; APC, antigen presenting cell; AST, aspartate aminotransferase; C-ANCA, cytoplasmic anti-neutrophil cytoplasmic antibodies; CCL, chemokine ligand; CTL, cytotoxic T lymphocytes; CYP2D6, cytochrome P450 2D6; DNA, deoxyribonucleic acid; ELISAs, enzymelinked immunosorbent assays; FOXP3, forkhead box P3; HCV, hepatitis C virus; Hep2, human epithelial 2; HLA, human leukocyte antigen; HS, healthy subjects; IAIHG, international autoimmune hepatitis group; IBD, inflammatory bowel disease; IFN, interferon; IgG, immunoglobulin G; IL, interleukin; LKM-1, liverkidney microsomal type 1; LSP, liver specific protein; LT, liver transplant; MELD, model for end-stage liver disease; MF, microfilament; MMF, mycophenolate mofetil; p-ANCA, perinuclear anti-neutrophil cytoplasmic antibodies; PBC, primary biliary cirrhosis; PSC, primary sclerosing cholangitis; SLA/LP, soluble liver antigen/liver pancreas; SLE, systemic lupus erythematosus; SMA, smooth muscle antibody; snRNPs, small nuclear ribonucleoproteins; TGF, transforming growth factor; Th, Thelper cell; TIM-3, Tcell immunoglobulin and mucin domain-3; TNF, tumor necrosis factor; Tregs, regulatory T cells.

Received: 31 October 2014; Revised: 08 December 2014; Accepted: 08 December 2014

DOI: $10.14218 /$ JCTH.2014.00032.

*Correspondence to: Giorgina Mieli-Vergani, Paediatric Liver, GI \& Nutrition Centre, King's College Hospital, Denmark Hill, London SE5 9RS, UK. Tel: +44-2032993357, Fax: +44-203-2994224, E-mail: giorgina.vergani@kcl.ac.uk involvement of diverse populations, including Th17 cells. A deeper understanding of the pathogenesis of AIH is likely to contribute to the development of novel treatments, such as the adoptive transfer of autologous expanded antigenspecific regulatory T-cells, which ultimately aim at restoring tolerance to liver-derived antigens.

(C) 2015 The Second Affiliated Hospital of Chongqing Medical University. Published by XIA \& HE Publishing Ltd. All rights reserved.

\section{Introduction}

The first decsription of autoimmune hepatitis (AIH) dates back to the 1950s, when Jan Waldenström reported a group of young women affected by severe and fluctuating persistent hepatitis associated with acneiform rashes, spider angiomas, anovulatory amenorrhea and profoundly elevated serum immunoglobulins. ${ }^{1}$ The presence of lupus erythematosus cells and of antinuclear antibody (ANA) seropositivity, subsequently led to the adoption of the term "lupoid hepatitis" and the idea that the condition stems from a loss of immunological tolerance. $^{2}$ The positive impact of steroid therapy, first recognised in the early 1960s, resulted in the publication of three controlled clinical trials which incontrovertibly showed the life-saving value of corticosteroids in the treatment of "HBsAg-negative hepatitis". ${ }^{3-5}$ The recognition that "chronic active autoimmune hepatitis", as it was then known, constituted a distinct clinical entity followed the systematic evaluation of its clinical symptoms, laboratory features, and molecular immunopathology. During two working meetings held in the early 1990s, the International Autoimmune Hepatitis Group (IAIHG), dropped 'chronic' and introduced the term "autoimmune hepatitis", as originally suggested by Ian Mackay in $1965,{ }^{6}$ since the disease frequently presents acutely and often has a fluctuating course, characterised by spontaneous remission, being therefore occasionally inactive. The IAIHG continues to monitor developments in the field regularly, and was responsible for the development of an initial scoring system for the diagnosis of $\mathrm{AIH}^{7}$ subsequently revised. ${ }^{8}$ More recently, a simplified system, designed for use in clinical practice, has been proposed by the group. ${ }^{9}$

Two types of AIH are recognised, based on the serological autoantibody profile: AIH type $1(\mathrm{AIH}-1)$ is defined by positivity for ANA and/or anti-smooth muscle antibody (SMA), whereas AIH type $2(\mathrm{AIH}-2)$ is characteriszed by the presence of anti-liver kidney microsomal type 1 antibody (anti-LKM-1) or anti-liver cytosol type 1 antibody (anti-LC-1). Besides the presence of autoantibodies, AIH is associated biochemically with elevated transaminase levels, histologically with interface hepatitis, and serologically with increased levels of IgG. Immunosuppressive therapy, which remains 
the mainstay of treatment, should be instituted as soon as the diagnosis is made, and, generally, the response is good. If left untreated, AIH usually progresses to liver failure requiring transplantation. The etiology of AIH is unknown, though both genetic and environmental factors are likely to be involved. An immune response targeting liver autoantigens, unrestrained because of the failure of immunoregulatory mechanisms, is thought to initiate and perpetuate the liver damage. ${ }^{10}$ Here, we review recent breakthroughs in our understanding of the pathogenesis of $\mathrm{AIH}$, linking them to advances in clinical practice.

\section{Epidemiology}

The actual prevalence of AIH is unknown. Few descriptive epidemiological studies are available, and the majority of them do not rely on standard criteria for patients' inclusion, since they were performed prior to the introduction of the IAIHG scoring system, and therefore no standardized way of evaluating patients was used. Moreover, early studies did not exclude patients with chronic hepatitis C. In a study conducted in a Norwegian population, Boberg et al. found a mean annual incidence of 1.9 cases per 100,000 people per year with a prevalence of 16.9 cases per 100,000 people. ${ }^{11}$ Another study, conducted in a Spanish population, reported an annual incidence of 0.83 cases per 100,000 inhabitants in the population aged $>14$ years with a prevalence of 11.6 cases per $100,000 .^{12}$ It should be pointed out, however, that this was a hospital-based study, consequently limited by tertiary referral bias, which can result in an underestimation of incidence and prevalence and an overestimation of disease severity. A study that examined the prevalence of AIH in Alaskan natives reported a prevalence of definite AIH in 34.5 cases per $100,000 .{ }^{13}$ This was the first study to use the IAIHG scoring system, and the rate observed was over twice as high as that of another population based study (i.e. the Norwegian one referred to earlier). A study from the United Kingdom, conducted in a secondary care referral center, showed that the annual incidence of AIH was 3.5 per 100,000 inhabitants. ${ }^{14}$ More recently, an epidemiological study carried out in New Zealand in which standardized inclusion criteria were deployed, reported an annual incidence of 2.0 cases of $\mathrm{AIH}$ per 100,000 and a point prevalence of 24.5 cases per $100,000 .{ }^{15}$ In Asia, most reports come from Japan, where $\mathrm{AIH}$ is considerably less frequent with an incidence estimated between 0.08 and 0.15 cases per 100,000 people per year. ${ }^{16,17}$ Similarly, AIH was long thought to be uncommon in China; ${ }^{18}$ however, with a more refined diagnostic work-up of patients, AIH has been increasingly reported in that country. ${ }^{19}$

The prevalence of AIH-2, which affects mainly children and young adults, is unknown, because the diagnosis is often overlooked. At King's College Hospital tertiary pediatric hepatology referral center, there has been a seven-fold increase in the incidence of both types of AIH over the last decade. ${ }^{20}$ AIH represents approximately $10 \%$ of some 400 new pediatric referrals per year; where two-third of the cases are $\mathrm{AIH}-1$, and one-third are $\mathrm{AIH}-2 .{ }^{20}$

$\mathrm{AIH}$, though characterized by a strong female preponderance (female/male $=3.6 / 1$ ), ${ }^{21}$ occurs in children and adults of both sexes. AIH was believed to be a disease of the young and middle aged, but it is now clear that it affects adults of all ages, including individuals older than $60 .^{22,23}$

\section{Pathogenesis}

\section{Genetics}

In $\mathrm{AIH}$, the strongest associations are located within the human leukocyte antigen (HLA)-DRB1 locus, with HLADRB1*03 and HLA-DRB1*04 conferring susceptibility in European and North American populations. ${ }^{8}$ These associations have been recently confirmed in the first AIH genomewide association study. ${ }^{24}$ Susceptibility to $\mathrm{AIH}-2$ is associated with HLA-DR*03 and HLA-DR*07 in the United Kingdom and Brazil. ${ }^{25}$ Non-HLA associations include CTLA $-4,{ }^{26}$ the tumor necrosis factor (TNF) $\alpha$ gene promoter, ${ }^{27}$ and $\mathrm{FAS}^{28}$ an important inducer of the extrinsic apoptotic pathway.

\section{Mechanisms of liver damage}

The mechanisms leading to autoimmune liver damage have been a focus of intense investigation over the past three decades. However, the initial trigger of liver centered autoimmunity remains elusive.

The histological picture of interface hepatitis, the hallmark of the disease and composed of lymphocytes, plasma cells, and macrophages, was the first evidence to suggest that an autoaggressive cellular immune attack was the basis of this condition. Whatever the initial trigger, this massive recruitment of activated inflammatory cells is likely to cause damage. Immunohistochemical studies performed in the early 1990s identified a predominance of $T$ lymphocytes expressing the $\alpha / \beta$ T cell receptor. ${ }^{29}$ Amongst T cells, the majority were positive for the CD4 helper/inducer phenotype and a sizable minority were positive for the CD8 cytotoxic phenotype. Lymphocytes of a non T cell lineage were fewer and included NK cells, macrophages, B cells, and plasma cells. ${ }^{29}$

Regardless of the factors triggering the autoimmune process, the pathogenic mechanism leading to liver damage is part of a complex scenario, involving the intervention of both innate and adaptive arms of the immune system. Liver damage is probably orchestrated by CD4 $4^{\text {pos }}$ lymphocytes that recognize a self-antigenic peptide. In the presence of the appropriate costimulatory signals, the autoimmune response is initiated after the peptide is embraced by an HLA class II molecule and presented by an antigen presenting cell (APC) to a naïve $C D 4^{\text {pos }} \mathrm{T}$ helper cell (Th0). Once activated, and depending on the type of cytokines present in the microenvironment and the nature of the antigen, Th0 cells can differentiate into: Th1, Th2, and Th17 cells. These effector cells initiate a cascade of immune reactions largely determined by the cytokines they produce: a) Th1 cells secrete mainly interleukin (IL) -2 and interferon (IFN) $-\gamma$; IFN- $\gamma$ is considered the main orchestrator of tissue damage since it not only stimulates CD8 cells, enhances the expression of HLA class I, and induces expression of HLA class II molecules on hepatocytes, ${ }^{30,31}$ but also activates monocytes/macrophages, which in turn release IL-1 and TNF- $\alpha$; b) Th2 cells produce IL-4, IL-10, and IL-13, cytokines that induce the maturation of $B$ cells into plasma cells, with consequent production of autoantibodies; c) Th17 cells, which arise in the presence of transforming growth factor (TGF)- $\beta$ and IL-6, produce IL-17, IL-22, TNF- $\alpha$, and chemokine ligand (CCL)$20 .{ }^{32}$ Th17 immunity has quite recently been associated in both mice and humans with autoimmune disease. ${ }^{33}$ These cells have been implicated in the pathogenesis of another 
autoimmune liver disease, primary biliary cirrhosis (PBC). ${ }^{34}$ Although their contribution to liver damage in AIH is still under investigation, a recent paper showed an increased number of Th17 cells in both the peripheral blood and liver of patients with AIH compared to healthy controls. ${ }^{35}$

If regulatory T cells (Tregs) are numerically and functionally impaired in $\mathrm{AIH}$, a number of effector responses, including direct action of cytotoxic $T$ lymphocytes (CTL), cytokines released by Th1, and possibly Th17 cells and monocytes/ macrophages, and complement activation or engagement of natural killer cells by autoantibodies bound to the hepatocyte surface, perpetuate liver cell destruction (Fig. 1). ${ }^{36}$

\section{Impairment of regulatory T-cells}

Several studies have reported that Tregs are numerically defective in AIH patients compared to healthy subjects (HS). A lower circulating frequency of $\mathrm{CD} 4^{\text {pos }} \mathrm{CD} 25^{\text {pos }} 37,38$ or $\mathrm{CD} 4^{\text {pos }} \mathrm{CD} 25^{\text {high }} 39$ Tregs has been reported in AIH patients compared to HS, and this defect is associated with lower forkhead box P3 (FOXP3) expression. ${ }^{39,40}$ Moreover, during immunosuppressive therapy, the circulating Treg frequency has been shown to increase to some extent, although not equating the levels seen in HS. ${ }^{37,39}$ In one study, however, the circulating frequency of $\mathrm{CD} 4^{\text {pos }} \mathrm{CD} 25^{\text {high }} \mathrm{CD} 127^{\text {neg }}$ FOXP3 ${ }^{\text {pos }}$ cells was equal in AIH patients and HS, and the frequency of this population was higher in patients with active disease compared to those in remission. ${ }^{41}$

In coculture with $C D 4^{\text {pos }} C D 25^{\text {neg }}$ cells, magnetically isolated $\mathrm{CD} 4^{\text {pos }} \mathrm{CD} 25^{\text {pos }}$ Tregs from AIH patients were less able to generate an antiinflammatory cytokine milieu rich in TGF $\beta$, suggesting that Tregs from AIH patients are ineffective promoters of linked-suppression. ${ }^{40}$ Magnetically isolated CD $4{ }^{\text {pos }} \mathrm{CD} 25^{\text {pos }}$ Tregs from AIH patients have impaired ability to suppress the proliferation of $C D 8^{\text {pos } 38}$ and $C D 4^{\text {pos }} C D 25^{\text {neg }} 39,42$ cell populations compared to HS. $\mathrm{CD} 4{ }^{\mathrm{pos}} \mathrm{CD} 25^{\text {pos }}$ Tregs from AIH patients are also ineffective suppressors of IFN $\gamma$ production by CD8 Tcells $^{38}$. Additionally, Tregs from AIH patients, but not HS, effectively enhance the activation of proinflammatory monocytes by increasing the level of spontaneous migration, the production of TNF $\alpha$, and the expression of TLR4. ${ }^{43}$ Magnetically isolated $\mathrm{CD} 4^{\text {pos }} \mathrm{CD} 25^{\text {pos }} \mathrm{CD} 127^{\text {neg }}$ Tregs from

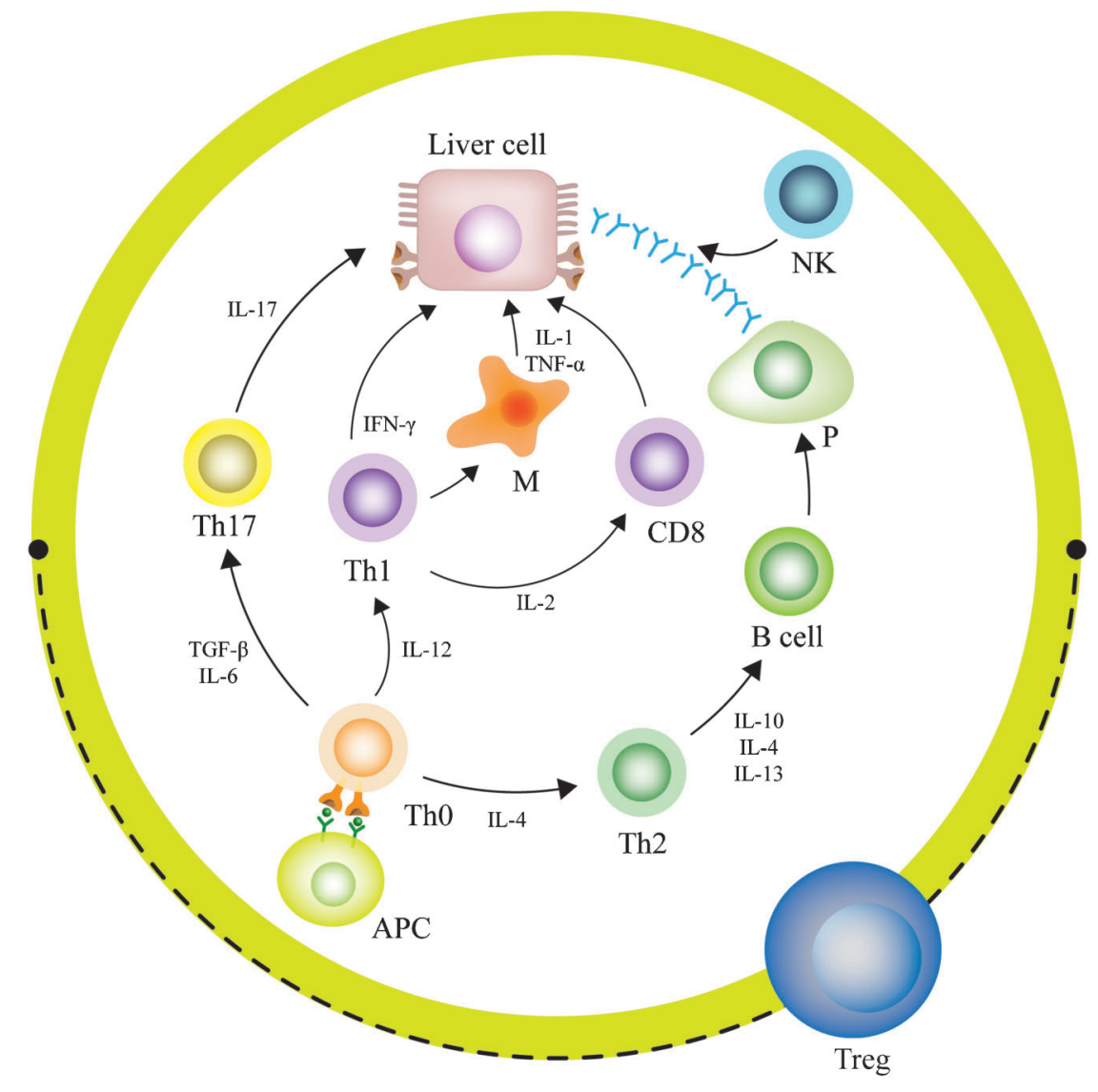

Fig. 1. Autoimmune attack to the liver cell. An autoantigenic peptide is presented to an uncommitted Thelper (Th0) lymphocyte within the HLA class II molecule of an antigen-presenting cell (APC). Th0 cells become activated and, according to the cytokines present in the microenvironment and the nature of the antigen, differentiate into Th1, Th2, or Th17 cells, initiating a series of immune reactions determined by the cytokines they produce: Th2 secrete mainly IL-4, IL-10, and IL-13 and direct autoantibody production by B lymphocytes; Th1 secrete IL-2 and IFN- $\gamma$, which stimulate cytotoxic T lymphocytes (CTL), enhance expression of class I, and induce expression of class II HLA molecules on hepatocytes and activate macrophages; activated macrophages release IL-1 and tumor necrosis factor alpha (TNF- $\alpha$ ). If regulatory T cells do not oppose, a variety of effector mechanisms are triggered: liver cell destruction could derive from the action of CTL; cytokines released by Th1 and recruited macrophages; complement activation; or engagement of Fc receptor-bearing cells, such as natural killer (NK) lymphocytes, by the autoantibody bound to the hepatocyte surface. The role of the recently described Th17 cells, which arise in the presence of transforming growth factor beta (TGF- $\beta$ ) and IL-6, is under investigation. 
AIH patients were also less able to suppress proliferation in AIH compared to $\mathrm{HS}^{42}$ although this defect was not observed in cytofluorimetrically isolated $C D 4^{\text {pos }} C D 25^{\text {high }} C D 127^{\text {neg }}$ cells. ${ }^{41}$ Tregs from AIH patients have been shown to express lower levels of galectin-9, and this defect is mirrored by reduced expression of the galectin- 9 ligand, T cell immunoglobulin, and mucin domain-3 (TIM-3) by $\mathrm{CD} 4^{\text {pos }} \mathrm{CD} 25^{\text {neg }}$ cells, suggesting that AIH may also be associated with effector cell resistance to Treg control. ${ }^{42}$

\section{Diagnosis}

The diagnosis of AIH is based on the presence of elevated transaminase and IgG levels, positivity for circulating autoantibodies, and a picture of interface hepatitis on histology. The criteria for the diagnosis of AIH have been established and revised by IAIHG. ${ }^{7,8}$ This diagnostic system, which includes positive and negative scores, grades clinical, laboratory, and histological features of $\mathrm{AIH}$, including response to treatment. Initially, the scoring system was devised mainly for research purposes. However, it also proved to be clinically useful in assessing patients with few or atypical features of the disease. ${ }^{44,45}$ In the IAIHG scoring system, differences between a definite and probable diagnosis of $\mathrm{AIH}$ relate mainly to the degree of serum gamma-globulin or IgG elevation, levels of ANA, SMA, or anti-LKM-1 and exposure to alcohol, medications, or infections that can cause liver injury. Cholestatic laboratory and histological changes carry a negative score. In rare cases, the presence of autoantibodies to asialoglycoprotein receptor (anti-ASGPR), LC-1, soluble liver antigen/liver pancreas (anti-SLA/LP), and atypical perinuclear anti-neutrophil cytoplasmic antibodies supports a probable diagnosis of AIH in the absence of conventional autoantibodies. Response to steroids strengthens the diagnosis of AIH and has been incorporated into the scoring system. A definite diagnosis before steroid treatment requires a score higher than 15 , while a definite diagnosis after steroid treatment requires a score greater than 17 (Table 1).

The diagnositic criteria for children are slightly different from those of adults. In view of the fact that healthy children are very rarely positive for autoantibodies, titers as low as 1:20 for ANA and SMA and 1:10 for anti-LKM-1 are compatible with the diagnoses of $\mathrm{AIH}-1$ and $\mathrm{AIH}-2$, respectively. ${ }^{46}$

Recently, a simplified scoring system has been proposed by the IAIHG. ${ }^{9}$ This system, intended to be used in the clinical practice, assesses only four criteria: autoantibodies, IgG, histology, and exclusion of viral hepatitis (Table 2).

\section{Laboratory abnormalities}

$\mathrm{AIH}$ is characterized by elevated levels of transaminases. In general, the increase in aspartate aminotransferase (AST) and alanine aminotransferase (ALT) levels is much more striking than that of bilirubin and alkaline phosphatase (AP) levels. Nonetheless, in some patients cholestasis is present; in these cases, extra-hepatic obstruction, cholestatic forms of viral hepatitis, drug-induced disease, PBC, primary sclerosing cholangitis (PSC), and overlap syndromes must be taken into consideration. ${ }^{47}$

Another laboratory feature typical of AIH, albeit not always present, is a generalized elevation of serum globulins and particularly gamma globulins mainly due to an increase in the
IgG fraction. ${ }^{48}$ The serum autoantibodies typically present include: ANA, SMA, anti-LKM-1, and anti-LC-1. Anti-mitochondrial antibodies (AMA), typically present in PBC, are occasionally present in patients with $\mathrm{AIH}^{49}$ Since autoantibodies may also be found in other liver diseases, their presence as such is not diagnostic of $\mathrm{AIH}$.

\section{Diagnostic autoantibodies}

\section{Anti-nuclear antibodies}

ANA, the first AIH-associated autoantibody, ${ }^{2}$ is readily detectable and gives a nuclear staining in the kidney, stomach, and liver sections. In most cases, its pattern, especially in the liver, is homogeneous, although a coarsely or finely speckled pattern is observed less frequently. ${ }^{50}$

Human epithelial 2 (Hep2) cells, laryngeal tumor cells characterized by prominent nuclei, should be used for a clearer definition of the nuclear pattern. However, they should not be used for screening purposes because of a high positivity rate in adult and pediatric healthy populations. ${ }^{51,52}$ In $\mathrm{AIH}$, the target antigens of ANA are heterogeneous and not completely defined. ANA have been found to be reactive with single- and double-stranded deoxyribonucleic acid (DNA), small nuclear ribonucleoproteins (sn-RNPs), centromeres, histones, chromatin, and cyclin A. ${ }^{53-55}$ The advent of new techniques using recombinant nuclear antigens and immunoassays will hopefully lead to a better definition of the target antigens of ANA, of their specificity for diagnosis, and of their possible role in the pathogenesis of $\mathrm{AIH}-1 .{ }^{56}$

ANA are present not only in other autoimmune disorders, such as systemic lupus erythematosus (SLE), Sjögren syndrome and systemic sclerosis, ${ }^{57}$ but also in patients with viral hepatitis, drug-induced hepatitis, and alcoholic and nonalcoholic fatty liver disease. ${ }^{58,59}$ Thus, although ANA are considered diagnostic markers for $\mathrm{AIH}$, they are not specific for AIH.

\section{Anti-smooth muscle antibodies}

SMA antibodies are detected in kidney, stomach, and liver sections, where they stain the smooth muscle contained in the wall of the arteries. In the stomach, they also stain the muscularis mucosa and the lamina propria. On the renal substrate, it is possible to visualize the vessels (V), glomeruli (G), and tubules (T) patterns. ${ }^{60}$ The VG and VGT patterns are more specific for AIH than the $\mathrm{V}$ pattern. The VGT pattern corresponds to the F-actin or microfilament (MF) pattern observed when cultured fibroblasts are used as substrate. ${ }^{61}$ Neither the VGT nor the antiMF patterns are, however, entirely specific for AIH. SMA are directed against components of the cytoskeleton, such as actin and non-actin components, including tubulin, vimentin, desmin, and skeletin. ${ }^{58}$ Like ANA, SMA are not specific for AIH, since their presence has also been reported in advanced liver disease of other etiologies, infectious diseases, and rheumatic disorders. ${ }^{62}$

\section{Anti-Liver-kidney-microsomal type 1 antibodies}

Anti-LKM-1 antibodies, the hallmark of AIH-2, stain the hepatocellular cytoplasm and the P3 portion of the renal tubules. Some confusion can occur between the immunofluorescence patterns of anti-LKM-1 and AMA because both 
Table 1. International autoimmune hepatitis group revised diagnostic scoring system

\begin{tabular}{|c|c|c|}
\hline Parameter & Feature & Score \\
\hline Sex & Female & +2 \\
\hline \multirow[t]{3}{*}{ ALP: AST (or ALT) ratio } & $>3$ & -2 \\
\hline & $1.5-3$ & 0 \\
\hline & $<1.5$ & +2 \\
\hline \multirow[t]{4}{*}{ Serum globulins or IgG (times above normal) } & $>2.0$ & +3 \\
\hline & $1.5-2.0$ & +2 \\
\hline & $1.0-1.5$ & +1 \\
\hline & $<1.0$ & 0 \\
\hline \multirow[t]{4}{*}{ ANA, SMA or anti-LKM-1 titers } & $>1: 80$ & +3 \\
\hline & $1: 80$ & +2 \\
\hline & $1: 40$ & +1 \\
\hline & $<1: 40$ & 0 \\
\hline AMA & Positive & -4 \\
\hline \multirow[t]{2}{*}{ Viral markers of active infection } & Positive & -3 \\
\hline & Negative & +3 \\
\hline \multirow[t]{2}{*}{ Hepatotoxic drug history } & Yes & -4 \\
\hline & No & +2 \\
\hline \multirow[t]{2}{*}{ Average alcohol } & $<25$ g/day & +2 \\
\hline & $>60 \mathrm{~g} /$ day & -2 \\
\hline \multirow[t]{6}{*}{ Histological features } & Interface hepatitis & +3 \\
\hline & Plasma cells & +1 \\
\hline & Rosettes & +1 \\
\hline & None of the above & -5 \\
\hline & Biliary changes $^{a}$ & -3 \\
\hline & Atypical changes ${ }^{b}$ & -3 \\
\hline Immune diseases & Thyroiditis, colitis, other & +2 \\
\hline HLA & DR3 or DR4 & +1 \\
\hline Seropositivity for other autoantibodies & Anti-SLA/LP, actin, ASGPR, pANNA & +2 \\
\hline \multirow[t]{2}{*}{ Response to therapy } & Remission & +2 \\
\hline & Relapse & +3 \\
\hline
\end{tabular}

Pre-treatment score >15: definite AIH; 10-15: probable AIH; Post-treatment score >17: definite AIH; 12-17: probable AIH.

ALP, alkaline phosphatase; AST, aspartate aminotransferase; ALT, alanine aminotransferase; IgG, immunoglobulin G; ANA, anti-nuclear antibody; SMA, smooth muscle antibody; anti-LKM-1, anti-liver kidney microsomal type 1 antibodies; AMA, anti-mitochondrial antibodies; SLA/LP, soluble liver antigen/liver pancreas; ASGPR, asialoglycoprotein receptor; p-ANNA, peripheral anti-nuclear neutrophil antibody (also known as atypical pANCA); HLA, human leukocyte antigen.

${ }^{a}$ Including granulomatous cholangitis, concentric periductal fibrosis, ductopenia, marginal bile duct proliferation and cholangiolitis; ${ }^{\mathrm{b}} \mathrm{Any}$ other prominent feature suggesting a different aetiology.

Adapted from Alvarez F. et al. ${ }^{8}$

autoantibodies stain the liver as well as the kidney. ${ }^{56}$ However, AMA stain the liver more faintly than anti-LKM-1 and mark the renal tubules more diffusely, while accentuating the distal tubules. Importantly, AMA stain gastric parietal cells while anti-KM-1 do not. ${ }^{63}$

The identification of the molecular targets of anti-LKM-1 (cytochrome P450 2D6 (CYP2D6)) and AMA (enzymes of the 2-oxo-acid dehydrogenase complexes), have led to the establishment of immune-assays based on the use of recombinant or purified antigens. Commercially available enzymelinked immunosorbent assays (ELISAs) are accurate for detection of anti-LKM-1, at least in the context of AIH-2, and for the detection of AMA. Thus, when a pattern remains difficult to interpret by immunofluorescence, the use of molecularly based immune-assays may be of help. ${ }^{46}$ Anti-LKM- 1 titer is clinically relevant if equal or higher than $1 / 40$ in adult patients and $1 / 10$ in subjects up to the age of 18 years. ${ }^{64}$ Intriguingly, anti-LKM-1 are also present in up to $10 \%$ of patients with chronic hepatitis $\mathrm{C}$ virus (HCV) infection, and their titer has been found to be associated with disease activity. ${ }^{65}$

\section{Anti-liver cytosol type 1 antibodies}

Anti-LC-1 was originally described, both in combination with anti-LKM-1 and in isolation, to define a clinical entity resembling $\mathrm{AIH}-2 .{ }^{66}$ Later, anti-LC-1 was also infrequently found in association with the serological markers of $\mathrm{AIH}-1^{67}$ and in patients with chronic hepatitis $C$ virus infection. ${ }^{68}$ The molecular target has been identified as the formiminotransferase cyclodeaminase, an enzyme involved in folate metabolism and most highly expressed in the liver $^{69}$ The presence and titer of anti-LC-1 antibodies correlate with 
Liberal R. et al: Autoimmune hepatitis

Table 2. Simplified criteria for the diagnosis of autoimmune hepatitis

\begin{tabular}{ll}
\hline Variable & Cut-off \\
\hline ANA or SMA & $\geqslant 1: 40$ \\
ANA or SMA & $\geqslant 1: 80$ \\
Or anti-LKM-1 & $\geqslant 1: 40$ \\
Or SLA & Positive \\
IgG & $>$ upper limite of normal \\
& $>1.10$ times upper limit of normal \\
Liver histology & Compatible with AIH \\
& Typical of AIH \\
Absence of viral hepatitis & Yes \\
\hline
\end{tabular}

Score $\geqslant 6$ : probable $A I H ; \geqslant 7$ : definite $A I H$.

ANA, anti-nuclear antibody; SMA, anti-smooth muscle antibody; anti-LKM-1, anti-liver kidney microsomal antibody type 1; SLA, soluble liver antigen; IgG, immunoglobulin G; AIH, autoimmune hepatitis.

${ }^{a}$ Addition of points achieved for all autoantibodies cannot exceed a maximum of 2 points.

Adapted from Hennes E.M. et al. ${ }^{9}$

disease activity and represent a potentially useful marker of residual hepatocellular inflammation in $\mathrm{AIH} .{ }^{70}$ The presence of anti-LC-1 in isolation scores positively towards a diagnosis of $\mathrm{AIH}-2$, allowing prompt initiation of treatment. ${ }^{71}$

\section{Anti-soluble liver antigen/liver-pancreas antigen antibodies}

Anti-SLA and anti-LP, originally described as individual antibodies, share the same antigenic target and have been subsequently identified as the same autoantibody. ${ }^{72}$ The presence of anti-SLA/LP in the absence of conventional antibodies, has led to the proposal of a third type of AIH (AIH-3). ${ }^{73}$ However, early reports used a cut-off point for levels of conventional autoantibodies higher than those currently recommended for the diagnosis of $\mathrm{AIH}$; therefore, the notion of AIH-3 has not been endorsed by the IAIHG. Anti-SLA/LP is highly specific for the diagnosis of AIH, and its detection at the time of presentation identifies patients with more severe disease and a worse outcome. ${ }^{74}$ Screening of cDNA expression libraries identified a UGA tRNA suppressorassociated antigenic protein (tRNP(ser)sec $)$, more precisely Ophosphoseryl-tRNA: selecysteinil-tRNA synthase (SepSecS), as the anti-SLA target. ${ }^{75}$

\section{Anti-neutrophil cytoplasmic antibodies}

ANCA react to cytoplasmic components of neutrophils, giving a perinuclear (p-ANCA) or cytoplasmic (c-ANCA) pattern. ${ }^{71,76}$ $c-A N C A$ mainly react with proteinase 3 and is found in Wegener granulomatosis; whereas p-ANCA react with myeloperoxidase and is frequently detected in microscopic polyangiitis. The p-ANCA detected in $\mathrm{AIH}-1$, as well as those in PSC and inflammatory bowel disease (IBD), have an atypical staining pattern, being associated with peripheral nuclear membrane components, hence the name of peripheral anti-nuclear neutrophil antibody (p-ANNA). ${ }^{77}$ In contrast to AIH-1, p-ANNA is virtually absent in AIH-2. Detection of $p$ ANNA can aid the diagnosis of AIH, particularly in the absence of other autoantibodies. ${ }^{64}$

\section{Anti-asialoglycoprotein receptor antibodies}

Attempts to identify putative auto-antigens specifically expressed on the hepatocyte surface in AIH have led to the description of a crude liver extract preparation known as the liver specific protein (LSP) and its major component the ASGPR. ${ }^{78}$ ASGPR, also designated as hepatic lectin, is a type II transmembrane glycoprotein. It is the only known liverspecific auto-antigen and is constitutively expressed on the hepatocellular membrane. Antibodies to ASGPR are observed in $88 \%$ of all patients with AIH and co-exist with ANA, SMA, or anti-LKM-1. ${ }^{58}$ However, they are not disease specific, as they can also be found in viral hepatitis, drug-induced hepatitis, and PBC. ${ }^{79}$ In $\mathrm{AIH}$, the levels of anti-ASGPR correlate with inflammatory disease activity and may be used as an additional marker to monitor treatment efficacy. ${ }^{80}$

\section{Histology}

Since transaminases and IgG levels do not reflect the extent of histological inflammatory activity or the presence or absence of cirrhosis, liver biopsy is mandatory; not only to confirm the diagnosis but also to evaluate the severity of liver damage.

Hepatitis at the portal-parenchymal interface, known as interface hepatitis (Fig. 2), is typical, but is not exclusively observed in $\mathrm{AIH} .{ }^{81}$ This picture is characterized by a lymphoplasmacytic infiltrate crossing the limiting plate and invading the liver parenchyma. Lymphocytes, plasma cells, and histiocytes surround individual dying hepatocytes at the portal-parenchymal interface and in the lobule. Though plasma cells are usually abundant at the interface and throughout the lobule, their presence in low number does not exclude the diagnosis of $\mathrm{AIH} .{ }^{71}$ Other lesions that may be present include hepatocyte swelling and pycnotic necrosis. Fibrosis is present in all but the mildest forms of the disease. In contrast to patients with an insidious course, those presenting with acute liver failure show tissue damage predominattly in the centrilobular area. ${ }^{82}$ However, many patients presenting with fulminant hepatic failure tend to have massive necrosis and multilobular collapse; importantly, they 


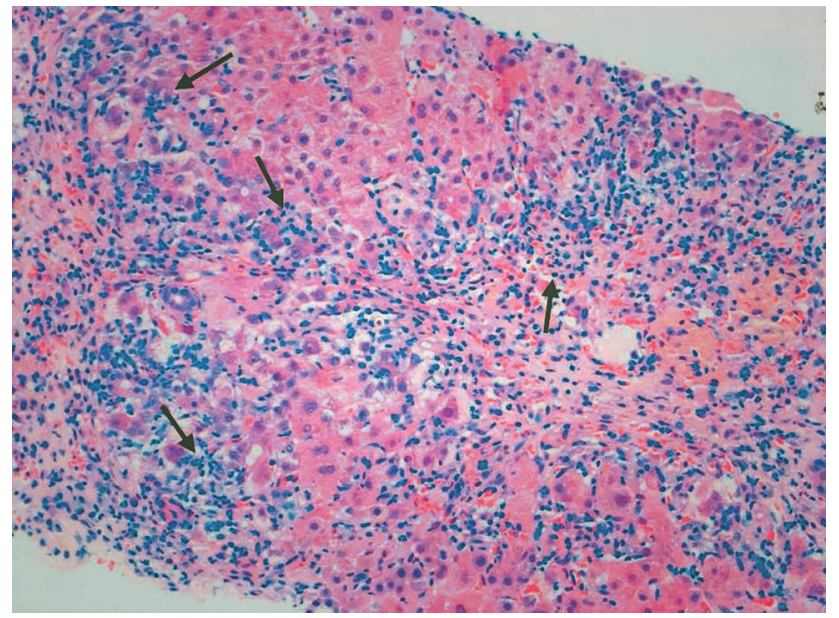

Fig. 2. Histology of autoimmune hepatitis. The portal and periportal inflammatory infiltrate characteristic of autoimmune hepatitis is composed of lymphocytes, monocytes/macrophages, and plasma cells (interface hepatitis, arrows). Hematoxylin \& eosin staining (Picture kindly provided by Dr. Alberto Quaglia, Institute of Liver Studies, King's College Hospital).

have less fibrosis than those presenting with a more insidious course. ${ }^{83}$

Despite the fact that sampling variation may occur in needle biopsy specimens, especially in the presence of cirrhosis, the severity of the histological appearance is usually of prognostic value. However, even patients with cirrhosis at presentation respond well to immunosuppressive treatment. ${ }^{84}$

Although the characteristic portal-parenchymal lesion usually spares the biliary tree, a small proportion of patients may show inflammatory changes surrounding the bile ducts, suggesting the presence of an overlap with sclerosing cholangitis, which occurs more frequently in the pediatric setting. ${ }^{85}$

\section{Treatment}

\section{Standard treatment}

In the early 70 s, three randomized clinical trials in adults with AIH provided the basis for current immunosuppressive regimens, collectively suggesting that treatment with prednisolone improves liver function tests, ameliorates symptoms, and prolongs survival. ${ }^{3-5}$ Although azathioprine did not induce remission when used on its own, it did allow for the maintenance of remission in association with a significantly reduced dose of steroids. ${ }^{86}$ Initial treatment with prednisone (or prednisolone) with or without azathioprine should be instituted as soon as the diagnosis is made (Table 3), not delayed for 6 months as suggested in the early studies. 87

The initial approach to therapy depends upon the histologic findings. ${ }^{83}$ Transaminase and IgG levels do not always correlate with histological damage and consequently provide limited help in respect to treatment initiation. Prompt treatment is indicated in patients with aggressive disease, usually children or young adults, and in any patient with evidence of interface hepatitis, with or without fibrosis or cirrhosis. ${ }^{21}$ In older patients with isolated portal inflammation (without interface hepatitis), institution of therapy is guided by AST and IgG levels and/or by the presence of symptoms. ${ }^{47}$ The therapeutic approach in patients with a milder form of the disease - those who may be asymptomatic or paucisymptomatic and are detected incidentally after discovery of abnormal liver function tests - is less clear. ${ }^{88}$ In these cases, the benefit of therapy is undefined and may be so low that the risk of corticosteroid side effects might outweigh its possible benefits; this is particularly relevant when starting therapy in post-menopausal women and elderly patients. ${ }^{22}$

Although some patients may remain in remission after drug treatment is withdrawn, most require long-term maintenance therapy. Despite the absence of firm guidelines, caution must be used when attempting to withdrawal immunosuppression within 2 years of diagnosis. ${ }^{21}$ During withdrawal attempts, it is essential to closely monitor liver function tests, as relapse may be severe and even fatal. Patients who have successfully stopped immunosuppression should undergo long-term follow-up, as relapse can occur even 10 years later. $^{88}$

\section{Alternative and new treatments}

In the group of patients that show failure to standard therapy and intolerance or low compliance to standard immunosuppression, alternative immunosuppressive treatments have been proposed. ${ }^{89}$ Decisions regarding the use of such regimens have to be based, however, on the basis of small series or case reports.

Mycophenolate mofetil (MMF) is a purine antagonist that selectively inhibits proliferation of activated lymphocytes. ${ }^{90}$ It has been reported to be effective in AIH patients intolerant to azathioprine. ${ }^{88}$ Therefore, in patients for whom standard immunosuppression fails to induce stable remission or who are intolerant to azathioprine, MMF, together with prednisolone, is currently the treatment of choice. ${ }^{21}$

Calcineurin inhibitors, cyclosporine and tacrolimus, have been used as a rescue treatment for difficult-to-treat cases of $\mathrm{AIH}$. As no large study in this subgroup of patients has been published, these drugs should be used with caution. ${ }^{88}$

Anti-TNF- $\alpha$ agents, such as infliximab, are commonly used to treat immune-mediated diseases such as rheumatoid arthritis, psoriasis, and IBD. There is anecdotal evidence that inflixmab is efficacious in the management of difficult-to-treat cases of AIH. ${ }^{91}$ In the largest published retrospective series, treatment with infliximab led to a decrease in transaminase and IgG levels in 11 difficult-to-treat adult patients with $\mathrm{AIH}$, although infectious complications occurred in seven of them. ${ }^{91}$ Moreover, and worryingly, infliximab therapy for other diseases has been associated with the induction of severe de novo AIH. ${ }^{92}$ Anecdotal evidence also suggestedsome benefit with the use of the anti $B$ cell monoclonal antibody rituximab in difficult-to-treat patients. ${ }^{93}$ However, the occurrence of severe infections is an important risk-factor associated with these biological treatments.

Budesonide is a corticosteroid with very high affinity for the glucorticoid receptor and high first pass liver metabolism; hence, it is presently receiving considerable attention as an alternative to prednisone or prednisolone as primary treatment of AIH. Although initial reports were somewhat contradictory, a recent large European study found that a combination of budesonide and azathioprine induced remission in $60 \%$ of non-cirrhotic patients, while medium-dose standard steroids and azathioprine only induced remission in $39 \%$ of patients. The budesonide group had also fewer 
Liberal R. et al: Autoimmune hepatitis

Table 3. Immunosuppressive treatment regimens for adults and children with autoimmune hepatitis

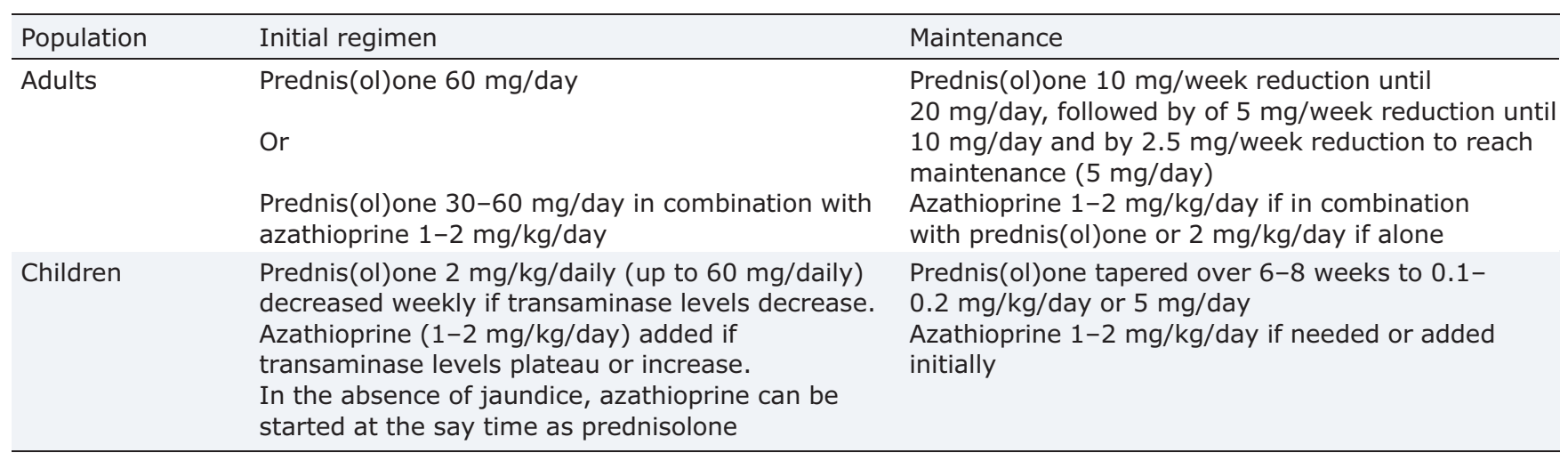

adverse effects. ${ }^{94}$ It should be noted, however, that this reported rate of remission was much lower than that seen in both adults and children $(\sim 80 \%)$ when a higher starting dose of prednisone was used. Moreover, because budesonide cannot be used in cirrhotic patients, representing at least a third of the AIH population, its clinical utility has limitations. ${ }^{95}$

\section{Liver transplantation}

AIH accounts for $2-3 \%$ of pediatric and $4-6 \%$ of adult liver transplants (LT) performed in Europe and the United States. ${ }^{96}$ LT is indicated for AIH patients with acute liver failure who do not respond to immunosuppressive treatment, present with end-stage chronic liver disease, and have hepatocellular carcinoma that meets the transplant criteria. ${ }^{97,98}$ Although patients with a chronic presentation of AIH typically respond well to immunosuppressive treatment, approximately $10 \%$ will eventually require LT. Patients who fail to reach remission after 4 years of therapy are the most common candidates for $\mathrm{LT}^{99}$ The indications for LT for end-stage chronic AIH are similar to those for PBC and other end-stage liver diseases. ${ }^{100,101}$

AIH can present at times with acute or even fulminant liver failure, requiring urgent $L T{ }^{102}$ The management of $\mathrm{AIH}$ patients with acute/fulminant hepatic failure is a therapeutic challenge, as experience is scarce and based on small retrospective studies. It is estimated that $8.7-19.8 \%$ of patients with AIH may have this form of presentation. ${ }^{102-106}$ According to published studies, the vast majority of them require $\mathrm{LT}$, although one-third may respond to corticosteroids. Factors associated with a greater likelihood of responding to corticosteroids are: Model for End-Stage Liver Disease (MELD) at admission $\leqslant 28$, absence of massive necrosis on histology, and stabilization or improvement of bilirubin levels and INR during the first 4 days of treatment. If there is no clinical or biochemichal improvement during this time frame, continued therapy with corticosteroids may be a futile exercise, as it is unlikely to change the course of the disease and may facilitate serious complications, particularly sepsis. If therapy with corticosteroids is maintained in these patients, it is imperative to pursue simultaneously assessment for LT. ${ }^{101}$

Though recurrence of $\mathrm{AIH}$ has been reported in between $20 \%$ and $30 \%$ of transplanted patients, ${ }^{101,107}$ a combination of prednisolone and a calcineurin inhibitor, the recommended immunosuppressive regimen after LT for $\mathrm{AIH},{ }^{107}$ leads to a very successful outcome with reported 5 and 10 year patient survivals of $80-90$ and $75 \%, 83$ respectively, and 1 and 5 year graft survivals of 84 and $75 \%$, respectively. ${ }^{83,108}$

\section{Conclusions}

The diagnosis of AIH should be considered during the diagnostic workup of any patient with increased liver enzyme levels. AIH is exquisitely responsive to immunosuppressive treatment, with symptom free long-term survival for the majority of patients. For patients who do not respond to standard treatment, or who are difficult-to-treat, MMF and, in the absence of a response, calcineurin inhibitors should be tried in addition to steroids. Persistent failure to respond or lack of adherence to treatment result in end-stage liver disease. These patients, and those with fulminant liver failure (encephalopathy grade II-IV) at diagnosis, will require liver transplantation. The pathogenesis of AIH is not fully understood, although there is increasing evidence that genetic susceptibility, molecular mimicry and impaired immunoregulatory networks contribute to the initiation and perpetuation of the autoimmune attack. Liver damage is thought to be mediated primarily by CD4 T cells, although recent studies support the involvement of diverse populations, including Th17 cells. Current studies are paving the way for the development of novel treatments aimed at reconstituting self-tolerance by specific immunologic maneuvers, such as adoptive transfer of autologous antigen-specific Tregs.

\section{Conflict of interest}

None

\section{Author contributions}

Writing the paper (RL, DV, GMV).

\section{References}

[1] Waldenström J. Leber, Blutprotein und Nahrungseiweiss. Deutsch Z Verdau Stoffwechselkr 1950;15:113-119.

[2] Mackay IR, Cowling DC, Taft LI. Lupoid hepatitis. Lancet 1956;271:13231326. doi: 10.1016/S0140-6736(56)91483-0.

[3] Cook GC, Mulligan R, Sherlock S. Controlled prospective trial of corticosteroid therapy in active chronic hepatitis. Q J Med 1971;40:159-185. doi: 10.1093/oxfordjournals.qjmed.a067264.

[4] Soloway RD, Summerskill WH, Baggenstoss AH, Geall MG, Gitnićk GL, Elveback IR, et al. Clinical, biochemical, and histological remission of severe 
chronic active liver disease: a controlled study of treatments and early prognosis. Gastroenterology 1972;63:820-833.

[5] Murray-Lyon IM, Stern RB, Williams R. Controlled trial of prednisone and azathioprine in active chronic hepatitis. Lancet 1973;1:735-737. doi: 10.1016/S0140-6736(73)92125-9.

[6] Mackay IR, Weiden S, Hasker J. Autoimmune hepatitis. Ann N Y Acad Sci 1965;124:767-780. doi: 10.1111/j.1749-6632.1965.tb19000.x.

[7] Johnson PJ, McFarlane IG. Meeting report: International Autoimmune Hepatitis Group. Hepatology 1993;18:998-1005. doi: 10.1002/ hep.1840180435.

[8] Alvarez F, Berg PA, Bianchi FB, Bianchi L, Burroughs AK, Cancado EL, et al. International Autoimmune Hepatitis Group Report: review of criteria for diagnosis of autoimmune hepatitis. J Hepatol 1999;31:929-938. doi: 10.1016/S0168-8278(99)80297-9.

[9] Hennes EM, Zeniya M, Czaja AJ, Parés A, Dalekos GN, Krawitt EL, et al. Simplified criteria for the diagnosis of autoimmune hepatitis. Hepatology 2008;48:169-176. doi: 10.1002/hep.22322.

[10] Liberal R, Longhi MS, Mieli-Vergani G, Vergani D. Pathogenesis of autoimmune hepatitis. Best Pract Res Clin Gastroenterol 2011;25:653664. doi: 10.1016/j.bpg.2011.09.009.

[11] Boberg KM, Aadland E, Jahnsen J, Raknerud N, Stiris M, Bell H. Incidence and prevalence of primary biliary cirrhosis, primary sclerosing cholangitis, and autoimmune hepatitis in a Norwegian population. Scand J Gastroenterol 1998;33:99-103.

[12] Primo J, Merino C, Fernandez J, Molés JR, Llorca P, Hinojosa J. [Incidence and prevalence of autoimmune hepatitis in the area of the Hospital de Sagunto (Spain)]. Gastroenterol Hepatol 2004;27:239-243. doi: 10.1016/ S0210-5705(03)70452-X

[13] Hurlburt KJ, McMahon BJ, Deubner H, Hsu-Trawinski BJ, Williams JL, Kowdley KV. Prevalence of autoimmune liver disease in Alaska Natives. Am J Gastroenterol 2002; 97:2402-2407. doi: 10.1111/j.1572-0241.2002. 06019.x.

[14] Whalley S, Puvanachandra P, Desai A, Kennedy H. Hepatology outpatient service provision in secondary care: a study of liver disease incidence and resource costs. Clin Med 2007;7:119-124. doi: 10.7861/clinmedicine.7-2119.

[15] Ngu JH, Bechly K, Chapman BA, Burt MJ, Barclay ML, Gearry RB, et al. Population-based epidemiology study of autoimmune hepatitis: a disease of older women? J Gastroenterol Hepatol 2010;25:1681-1686. doi: 10.1111/j.1440-1746.2010.06384.x.

[16] Nishioka M, Morshed SA, McFarlane IG. Geographical variation in the frequency and characteristics of autoimmune liver diseases. In: Krawitt EL, Wiesner RH, Nishioka M. Autoimmune liver diseases. 2nd ed. Amesterdam: Elsevier, 1998:413-424.

[17] Toda G, Zeniya M, Watanabe F, Imawari M, Kiyosawa K, Nishioka M, et al. Present status of autoimmune hepatitis in Japan-correlating the characteristics with international criteria in an area with a high rate of HCV infection. Japanese National Study Group of Autoimmune Hepatitis. J Hepatol 1997; 26:1207-1212. doi: 10.1016/S0168-8278(97)80453-9.

[18] Lam KC, Lai CL, Wu PC, Todd D. Etiological spectrum of liver cirrhosis in the Chinese. J Chronic Dis 1980;33:375-381. doi: 10.1016/0021-9681(80) 90047-8.

[19] Qiu D, Wang Q, Wang H, Xie Q, Zang G, Jiang H, et al. Validation of the simplified criteria for diagnosis of autoimmune hepatitis in Chinese patients. J Hepatol 2011;54:340-347. doi: 10.1016/j.jhep.2010.06.032.

[20] Vergani D, Mieli-Vergani G. Autoimmune hepatitis. In: Rodes J, Benhamou JP, Dufour JF. Textbook of hepatology: from basic science to clinical practicde. 3rd ed. London: Blackwell publishing, 2007:1089-1101.

[21] Manns MP, Czaja AJ, Gorham JD, Krawitt EL, Mieli-Vergani G, Vergani D, et al. Diagnosis and management of autoimmune hepatitis. Hepatology 2010;51:2193-2213. doi: 10.1002/hep.23584.

[22] Al-Chalabi T, Boccato S, Portmann BC, McFarlane IG, Heneghan MA. Autoimmune hepatitis (AIH) in the elderly: a systematic retrospective analysis of a large group of consecutive patients with definite AIH followed at a tertiary referral centre. J Hepatol 2006;45:575-583. doi: 10.1016/ j.jhep.2006.04.007.

[23] Czaja AJ, Carpenter HA. Distinctive clinical phenotype and treatment outcome of type 1 autoimmune hepatitis in the elderly. Hepatology 2006; 43:532-538. doi: 10.1002/hep.21074.

[24] de Boer YS, van Gerven NM, Zwiers A, Verwer B], van Hoek B, van Erpecum $\mathrm{KJ}$, et al. Genome-wide Association Study Identifies Variants Associated with Autoimmune Hepatitis Type-1. Gastroenterology 2014;147:443452.e5. doi: 10.1053/j.gastro.2014.04.022.

[25] Djilali-Saiah I, Fakhfakh A, Louafi H, Caillat-Zucman S, Debray D, Alvarez F. HLA class II influences humoral autoimmunity in patients with type 2 autoimmune hepatitis. J Hepatol 2006;45:844-850. doi: 10.1016/ j.jhep.2006.07.034.

[26] Agarwal K, Czaja AJ, Jones DE, Donaldson PT. Cytotoxic T Iymphocyte antigen-4 (CTLA-4) gene polymorphisms and susceptibility to type 1 autoimmune hepatitis. Hepatology 2000;31:49-53. doi: 10.1002/ hep. 510310110

[27] Cookson S, Constantini PK, Clare M, Underhill JA, Bernal W, Czaja AJ, et al. Frequency and nature of cytokine gene polymorphisms in type 1 autoimmune hepatitis. Hepatology 1999;30:851-856. doi: 10.1002/ hep.510300412.

[28] Agarwal K, Czaja AJ, Donaldson PT. A functional Fas promoter polymorphism is associated with a severe phenotype in type 1 autoimmune hepatitis characterized by early development of cirrhosis. Tissue Antigens 2007;69: 227-235. doi: 10.1111/j.1399-0039.2006.00794.x.

[29] Senaldi G, Portmann B, Mowat AP, Mieli-Vergani G, Vergani D. Immunohistochemical features of the portal tract mononuclear cell infiltrate in chronic aggressive hepatitis. Arch Dis Child 1992;67:14471453. doi: 10.1136/adc.67.12.1447.

[30] Lobo-Yeo A, Senaldi G, Portmann B, Mowat AP, Mieli-Vergani G, Vergani D. Class I and class II major histocompatibility complex antigen expression on hepatocytes: a study in children with liver disease. Hepatology 1990;12: 224-232. doi: 10.1002/hep.1840120208.

[31] Senaldi G, Lobo-Yeo A, Mowat AP, Mieli-Vergani G, Vergani D. Class I and class II major histocompatibility complex antigens on hepatocytes: importance of the method of detection and expression in histologically normal and diseased livers. J Clin Pathol 1991;44:107-114. doi: 10.1136/ jcp.44.2.107.

[32] Bettelli E, Carrier Y, Gao W, Korn T, Strom TB, Oukka M, et al. Reciprocal developmental pathways for the generation of pathogenic effector TH17 and regulatory T cells. Nature 2006;441:235-238. doi: 10.1038/nature04753.

[33] Miossec P, Korn T, Kuchroo VK. Interleukin-17 and type 17 helper T cells N Engl J Med 2009;361:888-898. doi: 10.1056/NEJMra0707449.

[34] Harada K, Shimoda S, Sato Y, Isse K, Ikeda H, Nakanuma Y. Periductal interleukin-17 production in association with biliary innate immunity contributes to the pathogenesis of cholangiopathy in primary biliary cirrhosis. Clin Exp Immunol 2009;157:261-270. doi: 10.1111/j.13652249.2009.03947.x.

[35] Zhao L, Tang Y, You Z, Wang Q, Liang S, Han X, et al. Interleukin-17 contributes to the pathogenesis of autoimmune hepatitis through inducing hepatic interleukin-6 expression. PLoS One 2011;6:e18909. doi: 10.1371/ journal.pone.0018909.

[36] Longhi MS, Ma Y, Mieli-Vergani G, Vergani D. Aetiopathogenesis of autoimmune hepatitis. J Autoimmun 2010;34:7-14. doi: 10.1016/ j.jaut.2009.08.010.

[37] Longhi MS, Ma Y, Bogdanos DP, Cheeseman P, Mieli-Vergani G, Vergani D. Impairment of $\mathrm{CD} 4(+) \mathrm{CD} 25(+)$ regulatory T-cells in autoimmune liver disease. J Hepatol 2004;41:31-37. doi: 10.1016/j.jhep.2004.03.008.

[38] Longhi MS, Ma Y, Mitry RR, Bogdanos DP, Heneghan M, Cheeseman P, et al. Effect of CD4+ CD25+ regulatory T-cells on CD8 T-cell function in patients with autoimmune hepatitis. J Autoimmun 2005;25:63-71. doi: 10.1016/ j.jaut.2005.05.001.

[39] Ferri S, Longhi MS, De Molo C, Lalanne C, Muratori P, Granito A, et al. A multifaceted imbalance of T cells with regulatory function characterizes type 1 autoimmune hepatitis. Hepatology 2010;52:999-1007. doi: 10.1002/ hep. 23792.

[40] Longhi MS, Hussain MJ, Mitry RR, Arora SK, Mieli-Vergani G, Vergani D, et al. Functional study of CD4+CD25+ regulatory $T$ cells in health and autoimmune hepatitis. J Immunol 2006;176:4484-4491. doi: 10.4049/ jimmunol.176.7.4484.

[41] Peiseler M, Sebode M, Franke B, Wortmann F, Schwinge D, Quaas A, et al FOXP3+ regulatory $T$ cells in autoimmune hepatitis are fully functional and not reduced in frequency. J Hepatol 2012;57:125-132. doi: 10.1016/ j.jhep.2012.02.029.

[42] Liberal R, Grant CR, Holder BS, Ma Y, Mieli-Vergani G, Vergani D, et al. The impaired immune regulation of autoimmune hepatitis is linked to a defective galectin-9/tim-3 pathway. Hepatology 2012;56:677-686. doi: 10.1002/hep.25682.

[43] Longhi MS, Mitry RR, Samyn M, Scalori A, Hussain MJ, Quaglia A, et al. Vigorous activation of monocytes in juvenile autoimmune liver disease escapes the control of regulatory T-cells. Hepatology 2009;50:130-142. doi: 10.1002/hep.22914.

[44] Czaja A, Carpenter HA. Validation of scoring system for diagnosis of autoimmune hepatitis. Dig Dis Sci 1996;41:305-314. doi: 10.1007/ BF02093820.

[45] Czaja AJ, Manns MP. Advances in the diagnosis, pathogenesis, and management of autoimmune hepatitis. Gastroenterology 2010;139:5872.e4. doi: $10.1053 /$ j.gastro.2010.04.053.

[46] Mieli-Vergani G, Heller S, Jara P, Vergani D, Chang MH, Fujisawa T, et al Autoimmune hepatitis. J Pediatr Gastroenterol Nutr 2009;49:158-164. doi: 10.1097/MPG.0b013e3181a1c265.

[47] Krawitt EL. Clinical features and management of autoimmune hepatitis. World J Gastroenterol 2008;14:3301-3305. doi: 10.3748/wjg.14.3301. 
[48] McFarlane IG. Definition and classification of autoimmune hepatitis. Semin Liver Dis 2002;22:317-324. doi: 10.1055/s-2002-35702.

[49] Bhat M, Guindi M, Heathcote EJ, Hirschfield GM. Transient development of anti-mitochondrial antibodies accompanies autoimmune hepatitis-sclerosing cholangitis overlap. Gut 2009;58:152-153. doi: 10.1136/ gut.2008.163220.

[50] Czaja AJ, Cassani F, Cataleta M, Valentini P, Bianchi FB. Antinuclear antibodies and patterns of nuclear immunofluorescence in type 1 autoimmune hepatitis. Dig Dis Sci 1997;42:1688-1696. doi: 10.1023/ A: 1018809431189.

[51] Tan EM, Feltkamp TE, Smolen JS, Butcher B, Dawkins R, Fritzler M], et al. Range of antinuclear antibodies in "healthy" individuals. Arthritis Rheum 1997;40:1601-1611. doi: 10.1002/art.1780400909.

[52] Hilario MO, Len CA, Roja SC, Terreri MT, Almeida G, Andrade LE. Frequency of antinuclear antibodies in healthy children and adolescents. Clin Pediatr (Phila) 2004;43:637-642. doi: 10.1177/000992280404300709.

[53] Burlingame RW, Rubin RL, Rosenberg AM. Autoantibodies to chromatin components in juvenile rheumatoid arthritis. Arthritis Rheum 1993;36: 836-841. doi: 10.1002/art.1780360615.

[54] Czaja AJ, Nishioka M, Morshed SA, Hachiya T. Patterns of nuclear immunofluorescence and reactivities to recombinant nuclear antigens in autoimmune hepatitis. Gastroenterology 1994;107:200-207.

[55] Strassburg CP, Alex B, Zindy F, Gerken G, Lüttig B, Meyer zum Büschenfelde $\mathrm{KH}$, et al. Identification of cyclin $\mathrm{A}$ as a molecular target of antinuclear antibodies (ANA) in hepatic and non-hepatic autoimmune diseases. J Hepato 1996;25:859-866. doi: 10.1016/S0168-8278(96)80290-X.

[56] Bogdanos DP, Invernizzi P, Mackay IR, Vergani D. Autoimmune liver serology: current diagnostic and clinical challenges. World J Gastroenterol 2008;14:3374-3387. doi: 10.3748/wjg.14.3374.

[57] Tan EM. Antinuclear antibodies: diagnostic markers for autoimmune diseases and probes for cell biology. Adv Immunol 1989;44:93-151. doi: 10.1016/S0065-2776(08)60641-0.

[58] Strassburg CP, Manns MP. Autoantibodies and autoantigens in autoimmune hepatitis. Semin Liver Dis 2002;22:339-352. doi: 10.1055/s-2002-35704.

[59] Adams LA, Lindor KD, Angulo P. The prevalence of autoantibodies and autoimmune hepatitis in patients with nonalcoholic Fatty liver disease. Am J Gastroenterol 2004;99:1316-1320. doi: 10.1111/j.15720241.2004.30444.x

[60] Bottazzo GF, Florin-Christensen A, Fairfax A, Swana G, Doniach D, Groeschel-Stewart U. Classification of smooth muscle autoantibodies detected by immunofluorescence. J Clin Pathol 1976;29:403-410. doi: 10.1136/jcp.29.5.403.

[61] Muratori P, Muratori L, Agostinelli D, Pappas G, Veronesi L, Granito A, et al. Smooth muscle antibodies and type 1 autoimmune hepatitis. Autoimmunity 2002;35:497-500. doi: 10.1080/0891693021000054066.

[62] Manns MP, Vogel A. Autoimmune hepatitis, from mechanisms to therapy. Hepatology 2006;43:S132-S144. doi: 10.1002/hep.21059.

[63] Rizzetto M, Swana G, Doniach D. Microsomal antibodies in active chronic hepatitis and other disorders. Clin Exp Immunol 1973;15:331-144.

[64] Vergani D, Alvarez F, Bianchi FB, Cançado EL, Mackay IR, Manns MP, et al. Liver autoimmune serology: a consensus statement from the committee for autoimmune serology of the International Autoimmune Hepatitis Group. J Hepatol 2004;41:677-683. doi: 10.1016/j.jhep.2004.08.002.

[65] Lenzi M, Ballardini G, Fusconi M, Cassani F, Selleri L, Volta U, et al. Type 2 autoimmune hepatitis and hepatitis $C$ virus infection. Lancet 1990;335: 258-259. doi: 10.1016/0140-6736(90)90070-L.

[66] Martini E, Abuaf N, Cavalli F, Durand V, Johanet C, Homberg JC. Antibody to liver cytosol (anti-LC1) in patients with autoimmune chronic active hepatitis type 2. Hepatology 1988;8:1662-1666. doi: 10.1002/hep.1840080632.

[67] Han S, Tredger M, Gregorio GV, Mieli-Vergani G, Vergani D. Anti-liver cytosolic antigen type 1 (LC1) antibodies in childhood autoimmune liver disease. Hepatology 1995;21:58-62.

[68] Lenzi M, Manotti P, Muratori L, Cataleta M, Ballardini G, Cassani F, et al. Liver cytosolic 1 antigen-antibody system in type 2 autoimmune hepatitis and hepatitis C virus infection. Gut 1995;36:749-754. doi: 10.1136/ gut.36.5.749.

[69] Lapierre P, Hajoui O, Homberg JC, Alvarez F. Formiminotransferase cyclodeaminase is an organ-specific autoantigen recognized by sera of patients with autoimmune hepatitis. Gastroenterology 1999;116:643-649. doi: 10.1016/S0016-5085(99)70186-1.

[70] Muratori L, Cataleta M, Muratori P, Lenzi M, Bianchi FB. Liver/kidney microsomal antibody type 1 and liver cytosol antibody type 1 concentrations in type 2 autoimmune hepatitis. Gut 1998;42:721-726. doi: 10.1136/gut.42.5.721.

[71] Vergani D, Longhi MS, Bogdanos DP, Ma Y, Mieli-Vergani G. Autoimmune hepatitis. Semin Immunopathol 2009;31:421-435. doi: 10.1007/s00281009-0170-7

[72] Wies I, Brunner S, Henninger J, Herkel J, Kanzler S, Meyer zum Büschenfelde $\mathrm{KH}$, et al. Identification of target antigen for SLA/LP autoantibodies in autoimmune hepatitis. Lancet 2000;355:1510-1515. doi: 10.1016/S0140-6736(00)02166-8.

[73] Manns M, Gerken G, Kyriatsoulis A, Staritz M, Meyer zum Büschenfelde KH. Characterisation of a new subgroup of autoimmune chronic active hepatitis by autoantibodies against a soluble liver antigen. Lancet 1987;1:292-294. doi: 10.1016/S0140-6736(87)92024-1.

[74] Ma Y, Okamoto M, Thomas MG, Bogdanos DP, Lopes AR, Portmann B, et al. Antibodies to conformational epitopes of soluble liver antigen define a severe form of autoimmune liver disease. Hepatology 2002;35:658-664. doi: 10.1053/jhep.2002.32092.

[75] Costa M, Rodriguez-Sanchez JL, Czaja AJ, Gelpí C. Isolation and characterization of cDNA encoding the antigenic protein of the human tRNP(Ser)Sec complex recognized by autoantibodies from patients withtype-1 autoimmune hepatitis. Clin Exp Immunol 2000;121:364-374. doi: 10.1046/ j.1365-2249.2000.01280.x.

[76] Hagen EC, Andrassy K, Chernok E, Daha MR, Gaskin G, Gross W, et al. The value of indirect immunofluorescence and solid phase techniques for ANCA detection. A report on the first phase of an international cooperative study on the standardization of ANCA assays. EEC/BCR Group for ANCA Assay Standardization. J Immunol Methods 1993;159:1-16. doi: 10.1016/00221759(93)90136-U.

[77] Bogdanos DP, Mieli-Vergani G, Vergani D. Autoantibodies and their antigens in autoimmune hepatitis. Semin Liver Dis 2009;29:241-253. doi: 10.1055/ s-0029-1233533.

[78] McFarlane IG, McFarlane BM, Major GN, Tolley P, Williams R. Identification of the hepatic asialo-glycoprotein receptor (hepatic lectin) as a component of liver specific membrane lipoprotein (LSP). Clin Exp Immunol 1984;55:347354.

[79] Treichel U, Gerken G, Rossol S, Rotthauwe HW, Meyer zum Büschenfelde $\mathrm{KH}$, Poralla T. Autoantibodies against the human asialoglycoprotein receptor: effects of therapy in autoimmune and virus-induced chronic active hepatitis. J Hepatol 1993;19:55-63. doi: 10.1016/S0168 8278(05)80176-X.

[80] Treichel U, McFarlane BM, Seki T, Krawitt EL, Alessi N, Stickel F, et al. Demographics of anti-asialoglycoprotein receptor autoantibodies in autoimmune hepatitis. Gastroenterology 1994;107:799-804. doi: 10.1016/ 0016-5085(94)90129-5.

[81] Czaja AJ, Carpenter HA. Histological findings in chronic hepatitis C with autoimmune features. Hepatology 1997;26:459-466. doi: 10.1002/ hep. 510260229 .

[82] Stravitz RT, Lefkowitch JH, Fontana RJ, Gershwin ME, Leung PS, Sterling RK, et al. Autoimmune acute liver failure: proposed clinical and histological criteria. Hepatology 2011;53:517-526. doi: 10.1002/hep.24080.

[83] Krawitt EL. Autoimmune hepatitis. N Engl J Med 2006;354:54-66. doi: 10.1056/NEJMra050408.

[84] Mieli-Vergani G, Vergani D. Autoimmune hepatitis in children. Clin Liver Dis 2002;6:623-634. doi: 10.1016/S1089-3261(02)00020-X.

[85] Gregorio GV, Portmann B, Karani J, Harrison P, Donaldson PT, Vergani D, et al. Autoimmune hepatitis/sclerosing cholangitis overlap syndrome in childhood: a 16-year prospective study. Hepatology 2001;33:544-553. doi: 10.1053/jhep.2001.22131.

[86] Johnson PJ, McFarlane IG, Williams R. Azathioprine for long-term maintenance of remission in autoimmune hepatitis. N Engl J Med 1995;333: 958-963. doi: 10.1056/NEJM199510123331502.

[87] Lohse AW, Mieli-Vergani G. Autoimmune hepatitis. J Hepatol 2011;55:171182. doi: 10.1016/j.jhep.2010.12.012.

[88] Vergani D, Mieli-Vergani G. Pharmacological management of autoimmune hepatitis. Expert Opin Pharmacother 2011;12:607-613. doi: 10.1517/ 14656566.2011.524206.

[89] Yeoman AD, Longhi MS, Heneghan MA. Review article: the modern management of autoimmune hepatitis. Aliment Pharmacol Ther 2010;31: 771-787. doi: 10.1111/j.1365 2036.2010.04241.x.

[90] Heneghan MA, McFarlane IG. Current and novel immunosuppressive therapy for autoimmune hepatitis. Hepatology 2002;35:7-13. doi: 10.1053/jhep.2002.30991.

[91] Weiler-Normann C, Schramm C, Quaas A, Wiegard C, Glaubke C, Pannicke $\mathrm{N}$, et al. Infliximab as a rescue-treatment in difficult-to-treat autoimmune hepatitis. J Hepatol 2012;58:529-534. doi: 10.1016/j.jhep.2012.11.010.

[92] Efe C, Purnak T, Ozaslan E, Wahlin S. Drug-induced autoimmune hepatitis caused by anti-tumor necrosis factor alpha agents. Hepatology 2010;52: 2246-2247. doi: 10.1002/hep.23834.

[93] Barth E, Clawson J. A Case of Autoimmune Hepatitis Treated with Rituximab. Case Rep Gastroenterol 2010;4:502-509. doi: 10.1159/ 000322693.

[94] Manns MP, Woynarowski M, Kreisel W, Lurie Y, Rust C, Zuckerman E, et al. Budesonide induces remission more effectively than prednisone in a controlled trial of patients with autoimmune hepatitis. Gastroenterology 2010;139:1198-1206. doi: 10.1053/j.gastro.2010.06.046.

[95] Hempfling W, Grunhage F, Dilger K, Reichel C, Beuers U, Sauerbruch T. Pharmacokinetics and pharmacodynamic action of budesonide in early- and 
late-stage primary biliary cirrhosis. Hepatology 2003;38:196-202. doi: 10.1053/jhep.2003.50266.

[96] Manns MP, Czaja AJ, Gorham JD, Krawitt EL, Mieli-Vergani G, Vergani D, et al. Diagnosis and management of autoimmune hepatitis. Hepatology 2010;51:2193-2213. doi: 10.1002/hep.23584.

[97] Reich DJ, Fiel I, Guarrera JV, Emre S, Guy SR, Schwartz ME, et al. Liver transplantation for autoimmune hepatitis. Hepatology 2000;32:693-700. doi: $10.1053 /$ jhep.2000.16666.

[98] Mottershead M, Neuberger J. Transplantation in autoimmune liver diseases. World J Gastroenterol 2008;14:3388-3395. doi: 10.3748/wjg.14.3388.

[99] Strassburg CP, Manns MP. Treatment of autoimmune hepatitis. Semin Liver Dis 2009;29:273-285. doi: 10.1055/s-0029-1233534.

[100] Liberal R, Grant CR, Mieli-Vergani G, Vergani D. Autoimmune hepatitis: a comprehensive review. J Autoimmun 2013;41:126-139. doi: 10.1016/ j.jaut.2012.11.002.

[101] Liberal R, Zen Y, Mieli-Vergani G, Vergani D. Liver transplantation and autoimmune liver diseases. Liver Transpl 2013;19:1065-1077. doi: $10.1002 /$ It.23704

[102] Ichai P, Duclos-Vallee JC, Guettier C, Hamida SB, Antonini T, Delvart V, et al. Usefulness of corticosteroids for the treatment of severe and fulminant forms of autoimmune hepatitis. Liver Transpl 2007;13:996-1003. doi: 10.1002/It.21036.
[103] Kessler WR, Cummings OW, Eckert G, Chalasani N, Lumeng L, Kwo PY Fulminant hepatic failure as the initial presentation of acute autoimmune hepatitis. Clin Gastroenterol Hepatol 2004;2:625-631. doi: 10.1016/ S1542-3565(04)00246-0.

[104] Potts JR, Verma S. Optimizing management in autoimmune hepatitis with liver failure at initial presentation. World J Gastroenterol 2011;17:20702075. doi: $10.3748 /$ wjg.v17.i16.2070

[105] Verma S, Gunuwan B, Mendler M, Govindrajan S, Redeker A. Factors predicting relapse and poor outcome in type I autoimmune hepatitis: role of cirrhosis development, patterns of transaminases during remission and plasma cell activity in the liver biopsy. Am J Gastroenterol 2004;99:15101516. doi: 10.1111/j.1572-0241.2004.30457.x.

[106] Miyake Y, Iwasaki Y, Terada R, Onishi T, Okamoto R, Sakai N, et al. Clinical characteristics of fulminant-type autoimmune hepatitis: an analysis of eleven cases. Aliment Pharmacol Ther 2006;23:1347-1353. doi: 10.1111/ j.1365-2036.2006.02894.x.

[107] Liberal R, Longhi MS, Grant CR, Mieli-Vergani G, Vergani D. Autoimmune hepatitis after liver transplantation. Clin Gastroenterol Hepatol 2012;10: 346-353. doi: 10.1016/j.cgh.2011.10.028.

[108] Futagawa Y, Terasaki PI. An analysis of the OPTN/UNOS Liver Transplant Registry. Clin Transpl 2004:315-329. 